\title{
Can Blockchain Technology Support Agricultural Sustainability?
}

\author{
Minerva Singh ${ }^{1}$ \\ ${ }^{1}$ Affiliation not available
}

January 11, 2022

Minerva Singh

Center For Environmental Policy (CEP), Imperial College London, London, UK

ms507@ic.ac.uk

\begin{abstract}
Blockchain technology is increasingly being supported for different agricultural commodity applications, including agricultural commodity tracing and provenance establishment. But many critical issues need to be addressed before the use of blockchain technology for this purpose becomes widespread both technologically and ethically. For that, I carried out a comparison of the different blockchain frameworks - mainly permissioned Hyperledger blockchain technology and Ethereum smart in terms of their agricultural sustainability applications. I also examined the role of Internet of Things (IoT) devices in supporting blockchain-driven sustainability. I identified how a lack of earth observation (EO) data undermines commodity provenance (and related ecological sustainability) establishment. However, the biggest threats to widespread blockchain technology adoption, especially for meeting sustainability standards include scalability issues and the lack of standard data protocols and governance measures.
\end{abstract}

\section{Introduction}

About three-quarters of the Earth's land surface has been altered by humans within the last millennium ${ }^{1}$. In addition to the growing demand for agricultural commodities in the Global South, the import of common agricultural commodities such as soybean, oil palm to developed countries has resulted in deforestation being displaced to the tropical forest-rich countries in the Global South ${ }^{2}$. Agricultural intensification in the Global South also has ecological consequences in terms of increased soil degradation ${ }^{3}$, damage to biodiversity ${ }^{4}$, fertiliser use $\mathrm{e}^{5}$ among others. Agricultural intensification, owing to ecological degradation and biodiversity impacts may have adverse effects on human health ${ }^{6}$. However, at the present time, there is limited traceability of many common agricultural commodities (and no standardised protocols to establish commodity origins) which has both ecological, human health and socio-economic concerns, including an increased risk of deforestation as a result of their sourcing ${ }^{7-9}$. Therefore being able to verify the origin of raw materials as well as learn more about the production process ${ }^{10}$ is vital to both promoting sustainable agriculture by minimizing its ecological and food safety-related concerns.

Blockchain is a disruptive technology that can facilitate traceability in agriculture supply chains through decentralised immutable public records ${ }^{11}$. Blockchain technology can act as a reliable source of truth about the state of farms, inventories and contracts in agriculture. Additionally, it can track the origins of agricultural commodities and thus help create trustworthy commodity supply chains ${ }^{12}$. For instance, the Brazilian meat producer JBS is deploying blockchain solutions to eradicate deforestation and farm-level malpractice by incorporating geospatial data (in the form of earth observation data and farm records) to monitor farms across 
the Amazon, Cerrado, Pantanal, Mata Atlântica and Caatinga biomes to identify cattle coming from farms created on recently deforested areas ${ }^{13}$. Blockchain technology holds the potential of improving transparency around farm-to-fork food safety and quality certification ${ }^{14}$. In addition to helping track the ecological footprint of the different agricultural commodities, blockchain technology can help establish the provenance of protected designation of origin (PDO) and protected geographical indication (PGI) agricultural commodities and ensure these can help support sustainability goals ${ }^{10,15}$. While earth observation (EO) data are increasingly being used in the context of ensuring agricultural production fulfils Sustainable Development Goals $(\mathrm{SDGs})^{16}$, they are yet to find widespread adoption within blockchain solutions. Additionally, blockchain frameworks have also been deployed for other agriculture-related activities, including payments without the need for third-party intervention. An agritech startup, AgriDigital, executed the world's first blockchainbased grain settlement. Since then, more than 1.6 million tons of grain have been transacted over the cloud, resulting in grower payments of $\$ 360$ million $^{17}$. Blockchain technology has been deployed for ensuring food sourcing transparency, adherence to safety standards and establishment of organic produce or geographic origins for a variety of products including wine, pork and fruits ${ }^{18}$. A comprehensive list of blockchain projects (and target food products) focused on the different aspects of agricultural commodity sourcing and supply has been provided in table 1 :

\begin{tabular}{|c|c|c|c|c|}
\hline Blockchain Company & $\begin{array}{l}\text { Food Company } \\
\text { Partners }\end{array}$ & Food Products & Country & References \\
\hline IBM & $\begin{array}{l}\text { Walmart, Carrefour, } \\
\text { Nestle, Unilever, } \\
\text { Farmer Connect, } \\
\text { Tyson, Foods, Raw } \\
\text { Seafoods Inc. Cermaq } \\
\text { salmon and Labeyrie, } \\
\text { El Ordeño }\end{array}$ & $\begin{array}{l}\text { Mousseline purée, } \\
\text { scallop, pork, lettuce, } \\
\text { mango slices, infant } \\
\text { nutrition, line } \\
\text { chicken, coffee beans, } \\
\text { seafoods (shrimps } \\
\text { and claims) }\end{array}$ & $\begin{array}{l}\text { US, China, } \\
\text { UK, France, } \\
\text { Ecuador }\end{array}$ & $\begin{array}{l}\text { Armonk } \\
\text { (2017), IBM } \\
\text { (2019), IBM } \\
\text { (2020) Kamath } \\
\text { (2018) }\end{array}$ \\
\hline SAP & $\begin{array}{l}\text { Target, Kelloggs, Tate \& } \\
\text { Lyle, Johnsonville, } \\
\text { Natura \& Co and Maple } \\
\text { Leaf, Bumble Bee }\end{array}$ & yellowfin tuna, & US & Lawton (2019) \\
\hline FoodlogIQ & $\begin{array}{l}\text { Tyson Foods, Subway, } \\
\text { UK's Food Standards } \\
\text { Agency, Testo, AgBiome } \\
\text { Innovations, }\end{array}$ & Tomato, coffee, & US & $\begin{array}{l}\text { Jones (2018a), } \\
\text { Jones (2018b) }\end{array}$ \\
\hline SIM & Refresco, Albert Heijn & Orange juice & Dutch & Hejin (2018) \\
\hline JD.com & InterAgri & $\begin{array}{l}\text { Pure Black Angus } \\
\text { Beef }\end{array}$ & $\begin{array}{l}\text { Australia, } \\
\text { China }\end{array}$ & JD.com (2018) \\
\hline OpenSC & Nestlé & Milk and palm oil & $\begin{array}{l}\text { Switzerland, } \\
\text { New Zealand }\end{array}$ & Nestlé (2019) \\
\hline Origin'Trail\&TagItSmart & Plantaze & Grape, wine, & $\begin{array}{l}\text { Montenegro, } \\
\text { China }\end{array}$ & $\begin{array}{l}\text { OriginTrail } \\
(2018)\end{array}$ \\
\hline BloomBloc & $\begin{array}{l}\text { Malaysian Palm Oil } \\
\text { Council (MPOC) }\end{array}$ & Palm oil & Malaysia & $\begin{array}{l}\text { Bernama } \\
(2020)\end{array}$ \\
\hline
\end{tabular}

Table 1: Agricultural Blockchain Projects ${ }^{19}$

While the adoption of blockchain technology for agricultural commodity tracing is a positive step, there are many critical issues that need to be addressed before the use of blockchain technology for this purpose 
becomes widespread both technologically and ethically. One of the most fundamental challenges facing largescale meaningful adoption is the limited research done to identify the Key Data Elements needed to ensure blockchain technology can be implemented consistently for different commodities and regions ${ }^{20}$. Owing to the lack of pre-defined frameworks to help determine what data are needed to meaningfully track agricultural commodity origins it is arguably difficult to scale up blockchain technology beyond the case-study scale. Figure 1 defines the key conceptual blocks that go into designing blockchains for operationalising supply chain traceability.

\section{Traceability}

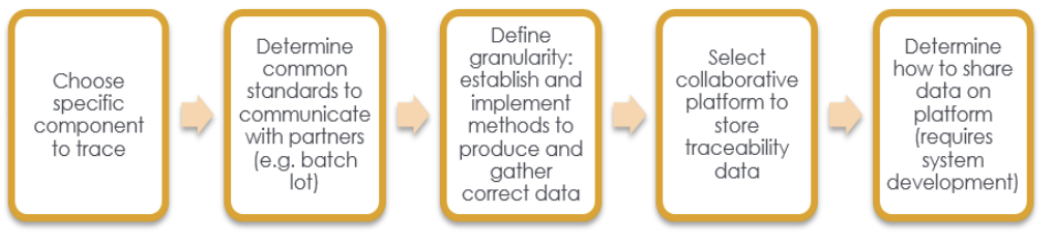

Fig. 4. Supply Chain Traceability.

Figure 1: Components of Supply Chain Traceability ${ }^{21}$

When operationalised in real-life, blockchain technology can allow a farmer/producer to use a mobile device app to track how their produce is sorted and when it reaches the client in a blockchain-enabled stream restraint. Transporters can see every piece of the crop in the inventory, allowing them to see any superiority issues quickly. Transport becomes more independent by participating in information barriers in the storehouse. The information created and managed on the blockchain can be studied to identify practices that can be altered to achieve the desired sustainability or economic goals. Clients can scan an item at a store to learn where it came from, who cultivated it, how long it's been in stock, and other information ${ }^{22}$. In addition to supply chain transparency, blockchains can help address several other agriculture-related issues, including remittances for smaller farmers and land registration as shown in figure 2 . 


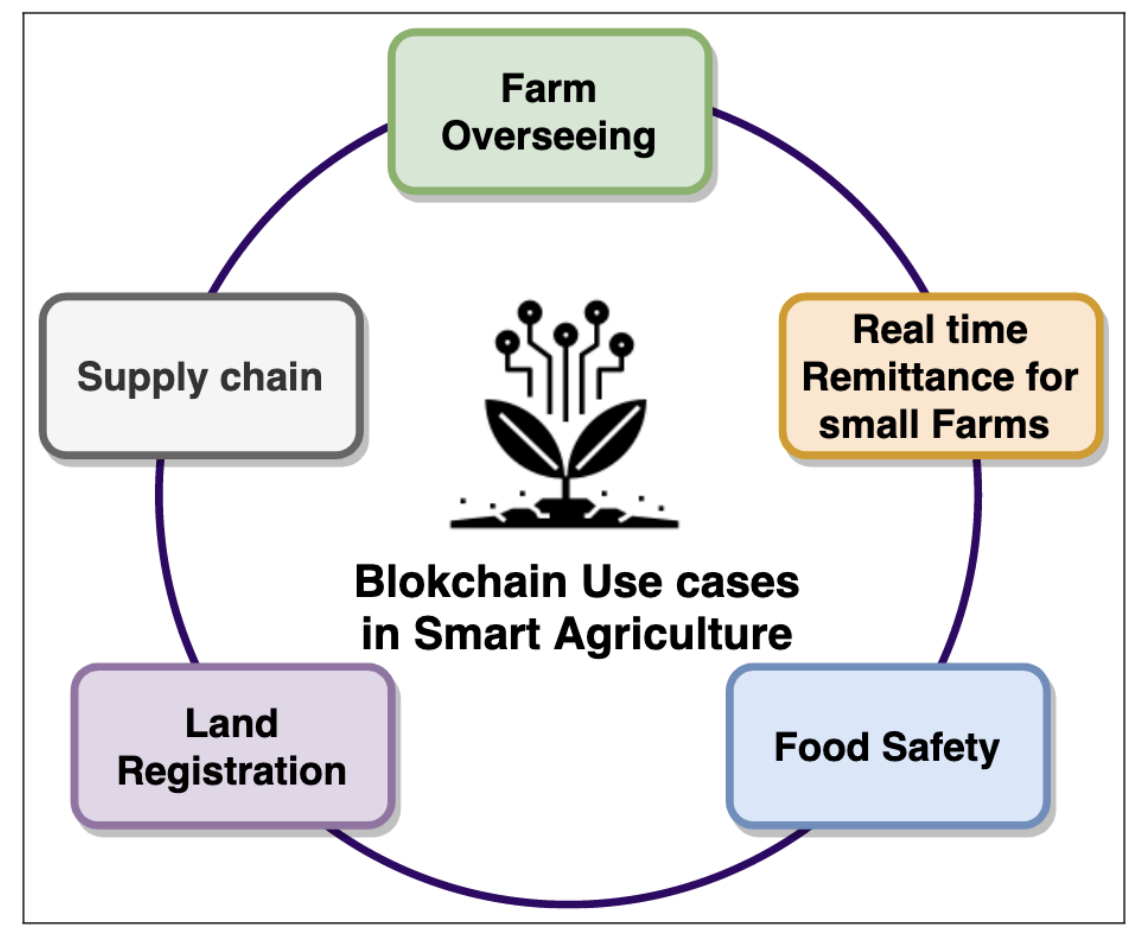

Figure 2: Use of Blockchains For Agricultural Sustainability ${ }^{23}$

The issue of land registration, at first glance, does not seem to have a significant bearing on food safety. However, in many developing countries, the existing land records available are poorly administered. Blockchain technologies, such as those hosted on the Ethereum blockchain offer the possibility of improving the land registration process and ensuring tenure rights. Blockchain technology also has been recommended as a way of improving food security by ensuring increased transparency and improving efficiency ${ }^{24}$. This is an important social issue and indeed, by developing individual blockchain solutions for different agricultural sustainability aspects, it could be possible to develop a full-stack blockchain-powered agricultural sustainability framework.

Some of the common blockchain scalability challenges include scalability ${ }^{25}$, tradeoffs between blockchain security and computational efficiency ${ }^{20}$ (including identifying blockchain frameworks that minimize energy consumption while meeting the project goals), intellectual property issues ${ }^{20}$ among others. Arguably, developing these conceptual frameworks and a critical comparison of the different blockchain frameworks (proofof-stake vs proof-of-work consensus, permissioned vs permissionless blockchains, smart contracts) ${ }^{26}$ is vital for enabling the scaling-up and mainstreaming of blockchain technology for supporting deforestation-free agricultural commodity sourcing. Qualitatively identifying the most energy-efficient alternative to the computationally demanding Bitcoin proof-of-work (POW) by comparing the ability of less-energy consuming Proof-of-Stake smart contract-based frameworks (such as those provided by Ethereum or Cardano) ${ }^{14}$, Hyperledgers for creating immutable records of agricultural commodity provenance and sourcing conditions ${ }^{27}$ (in this case, the deforestation footprints underpinning the sourcing farms). Indeed different parts of the agricultural commodity supply chain could lend themselves to different blockchain technologies (figure 3). 


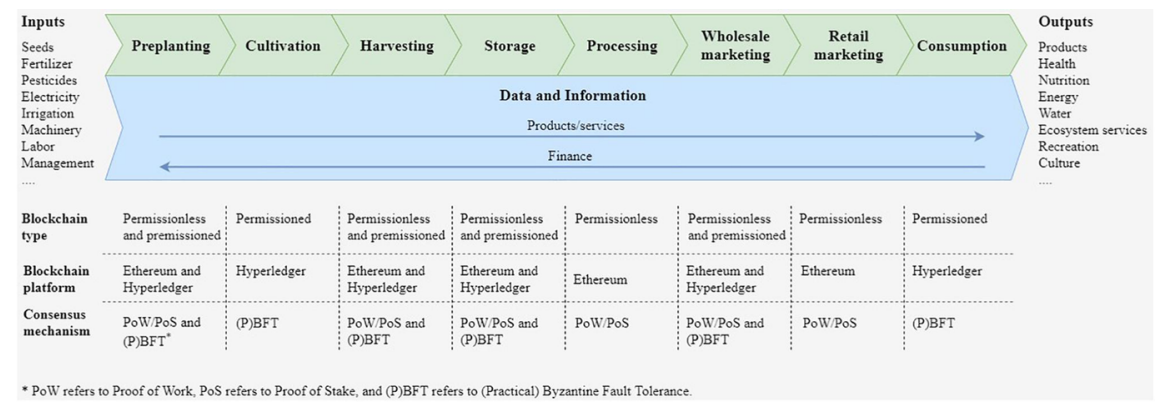

Figure 3: Blockchain Frameworks To Support Transparency At Different Points Of the Supply Chain ${ }^{28}$

Given the value proposition, different blockchain frameworks can provide to the different parts of the supply chain, scalable applications will also have to focus on interoperability issues. The different blockchain frameworks have their own pros and cons and indeed these frameworks can also be used together to achieve the desired traceability goals. In this review, we will explore the pros and cons of the most relevant blockchain solutions in supporting different aspects of agricultural commodity supply chain sustainability.

\section{Critical Examination of the Different Blockchain Frameworks Used For Establishing Agricul- tural Traceability}

Before delving deeper into examining specific blockchain frameworks, it is important to acquaint ourselves with the different blockchain paradigms. Broadly speaking, the Bitcoin and Ethereum blockchains are examples of public blockchains. Anyone can join and participate in a public blockchain. On the other hand, permissioned blockchains are a compromise between public and private blockchains and enable stakeholder participation, albeit with restrictions (such as needing identity verification). The Hyperledger framework that is commonly used in agricultural provenance applications is an example of permissioned blockchains.

\subsection{Hyperledgers}

In the food and agriculture industry, permissioned blockchain frameworks (such as Hyperledger) grant users specific rights over records (i.e., more centralised governance) and are built on a specific family of opensource distributed ledger frameworks. HyperLedger creates a consortium chain through a channel and uses membership service providers (MSPs) to control the permissions of nodes. Channels are independent communication channels between members that members belonging to them can only see transactions sent in them ${ }^{29}$. Within the Hyperledger family, Fabric (the platform on which IBM's blockchain is built) and Sawtooth enable industries to build their own permissioned blockchain networks ${ }^{30}$ are the most common frameworks. The IBM Farmer Connect blockchain platform, which is underpinned by the Hyperledger framework has been deployed by coffee manufacturers to establish the provenance of their coffee. For instance, UCC Coffee's Orangutan coffee can now be traced back to its Indonesian origin using farmer connect's 'Thank My Farmer'31. Walmart also deployed IBM's Hyperledger Fabric framework to improve food safety transparency and ensure complete end-to-end traceability ${ }^{32}$. A number of companies have committed to exploring the use of blockchain technology in food safety management and implementing it via the Hyperledger framework. Along with Wal-Mart, Alibaba and JD.com are implementing blockchain food traceability projects and using blockchain technology to track the entire process of food production, processing, and sale. Applied Hyperledger blockchain technology to food supply chain management in 2016 by Wal-Mart, Tsinghua University, and IBM as a pilot study to explore practical applications of blockchain technology. The studies explored the pork supply chain in China and the mango supply chain in the U.S. As part of a partnership with IBM, the 10 largest food and fast-moving consumer goods (FMCG) suppliers, including Wal-Mart, Nestle, Dole, and Golden Food, integrated blockchain into its supply chain to detect food suppliers' misconduct more quickly. IBM's Hyperledger blockchain platform is being used in this partnership to help food companies improve the visibility and traceability of their supply chains and ensure food safety ${ }^{28}$. 
Hyperledger is a private distributed ledger technology (DLT) that can facilitate agricultural commodity traceability, which begs the question of what it is and what are its pros and cons. It does so by making farm activities and produce histories easily accessible to consumers, tracking the transportation of products by carriers up until delivery, and facilitating the recording of farm activities by farmers. Farming environments are logged using IoT, and the quality of farms during plantation is analyzed ${ }^{33}$. Two of the most developed Hyperledger frameworks (for permissioned and permissionless blockchain networks) are Fabric (for permissioned blockchain networks) and Sawtooth (for permissioned blockchain networks). In addition to a variety of smart contract languages, these frameworks are enterprise-grade technologies utilised by many businesses, developers, and users. In particular, IBM supports Hyperledger Fabric. In comparison with the more popular Hyperledger Fabric, Sawtooth is the most powerful and robust blockchain framework, allowing for seamless interoperability with other blockchains ${ }^{17}$. Figure 4 shows the scheme of using Hyperledger within supply chains

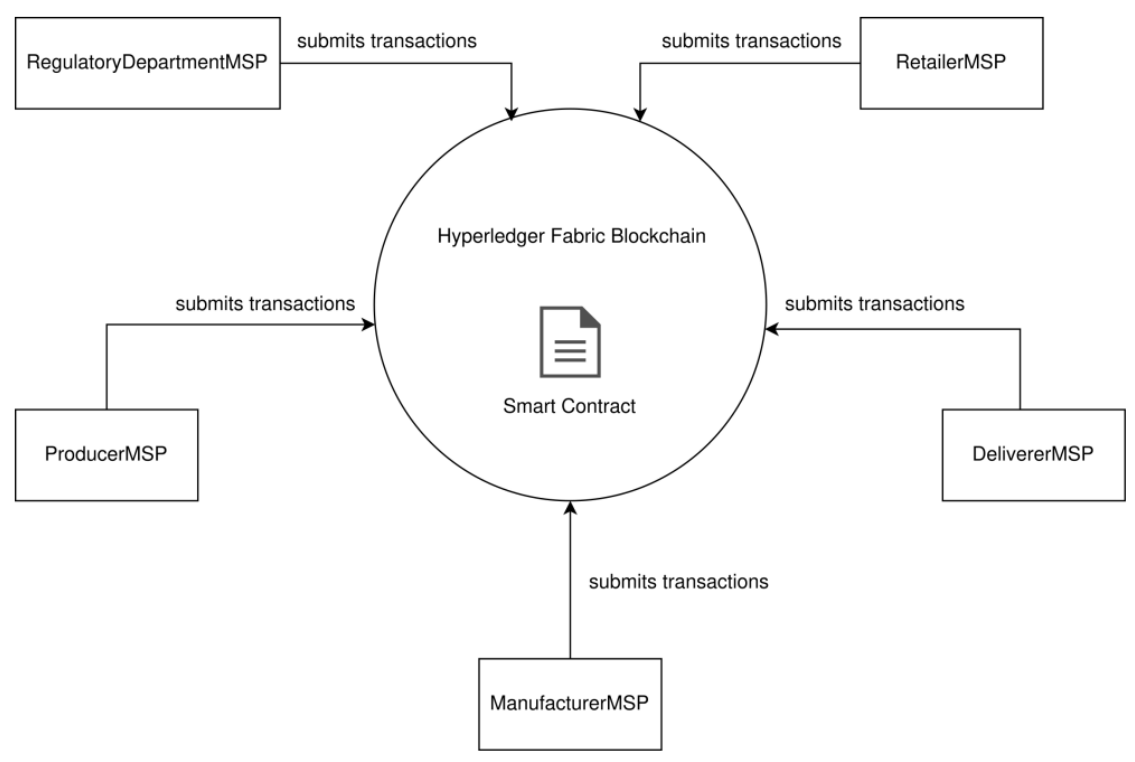

Figure 4: Typical agri-food supply chain scenario ${ }^{34}$

The Hyperledger Fabric framework is based on the Linux Foundation's open-source project. It aims to develop an extensible blockchain development framework that provides solutions for enterprise-level blockchain applications by allowing multiple parties to be involved in the development, deployment, and operation of the consortium blockchain platform ${ }^{35}$. With Hyperledger Fabric we can create an operating model that is low-cost and efficient, known as a federated chain model, based on public chains ${ }^{36}$

Hyperledger-based frameworks also offer the potential of ensuring fair price provisions for cultivators who live mainly in the Global South. The Hyperledger-implemented coffee transparency evaluation involves establishing coffee bean provenance, along with its quality and freshness and identifying supply chain bottlenecks ${ }^{37}$. Apart from establishing provenance, the system also helped establish full price transparency to ensure producers receive fair prices. Hyperledger-based systems like this can also ensure transparency for producers by digitizing the paper trail and sharing audits to demonstrate that they use and promote sustainable farm practices $^{37}$. While Hyperledger applications are preferred in a business context ${ }^{37}$ they are disadvantageous in high cost, slow data transition rate, low security. ${ }^{38}$ More importantly, permissioned blockchains such as Hyperledger do not allow general users to verify and trust the product. This defeats the purpose of utilizing blockchain technology. It will be very difficult to identify manipulations, whether they are done at the backend by a third party or an authorized party, in the absence of external validators. Permissionless blockchains 
such as those offered by Ethereum, on the other hand, are open to general users ${ }^{14}$.

\subsection{Ethereum (ETH) Smart Contracts}

The blockchain allows us to eliminate intermediaries, but the promises and trust boundaries between contributing parties often require what is called a smart contract ${ }^{39}$. Smart contracts are contracts that can be completed automatically without human interaction. Smart contracts allow anyone to exchange money, property, or shares in an easy and transparent way, without the need for a middleman ${ }^{40}$. The need for a middleman is eliminated through the use of computerized transaction protocols that implement the terms of a contract. These contractual clauses are converted into code and integrated into hardware or software so that the code gets implemented by itself (without trusted intermediaries). Figure 5 shows how smart contracts enable commodities to be transacted across a supply chain without needing third party intervention ${ }^{41}$.

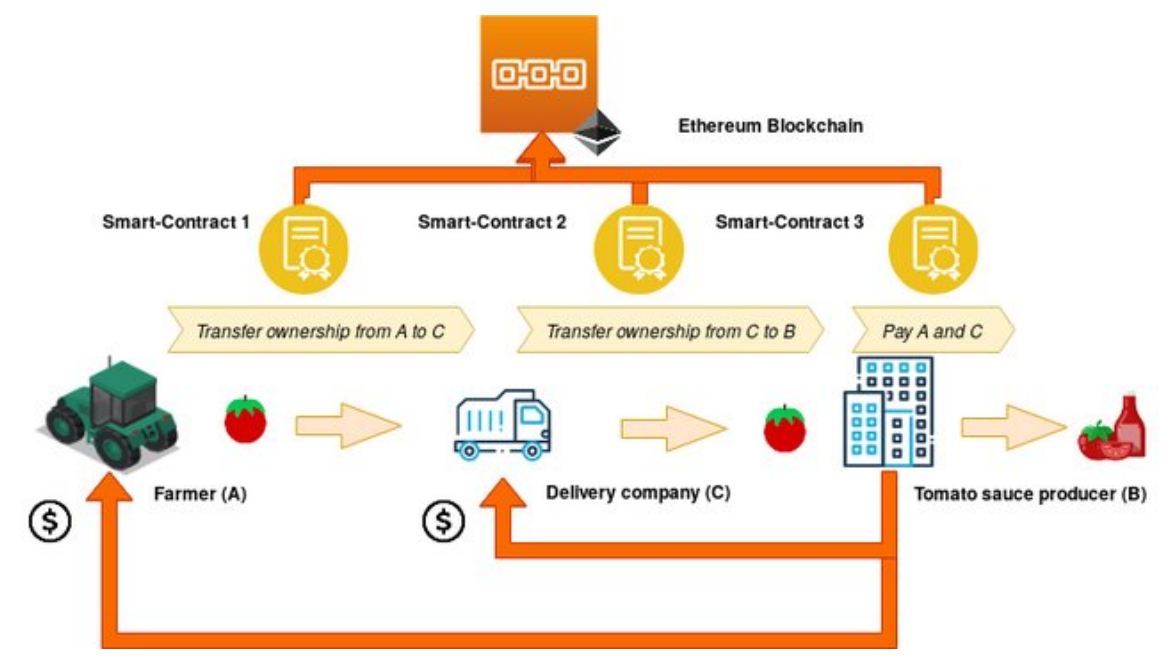

Figure 5: A Smart Contract Mediated Supply Chain ${ }^{41}$

Smart contract technology was first developed on the Ethereum blockchain ${ }^{14}$. Owing to their ability to eliminate third-party roles, Ethereum based smart contracts are increasingly being deployed for agricultural insurance in many parts of the Global South ${ }^{28,42,43}$. In addition to peerless insurance and payment settlements, smart contracts also allow for establishing agricultural commodity origins and ensuring expected standards (for instance, such as those needed for organic certification are being met). Smart contracts can help monitor and manage all communications and transactions within the supply chain network among all stakeholders. They verify every transaction, which is recorded and stored in a centralized interplanetary file system database ensuring transparency and security ${ }^{14}$.

An Ethereum blockchain-based solution has been suggested as a way of establishing that organic vegetables are meeting the requisite standards in terms of cultivation conditions and allowing them to sell their produce directly to consumers ${ }^{44}$. Ethereum blockchain and smart contracts were used to trace, track, and perform transactions in soybean supply chains with the view of improving transparency and visibility. Participants in the supply chain all have Ethereum accounts with unique Ethereum Addresses (EAs) that identify them uniquely. Basically, Ethereum accounts consist of an EA and public and private keys which are used for cryptographically and digitally signing and validating data within each transaction, as well as associating each transaction with a specific account ${ }^{11}$. The entire soybean farm-to-fork blockchain framework has been demonstrated in figure 6 : 


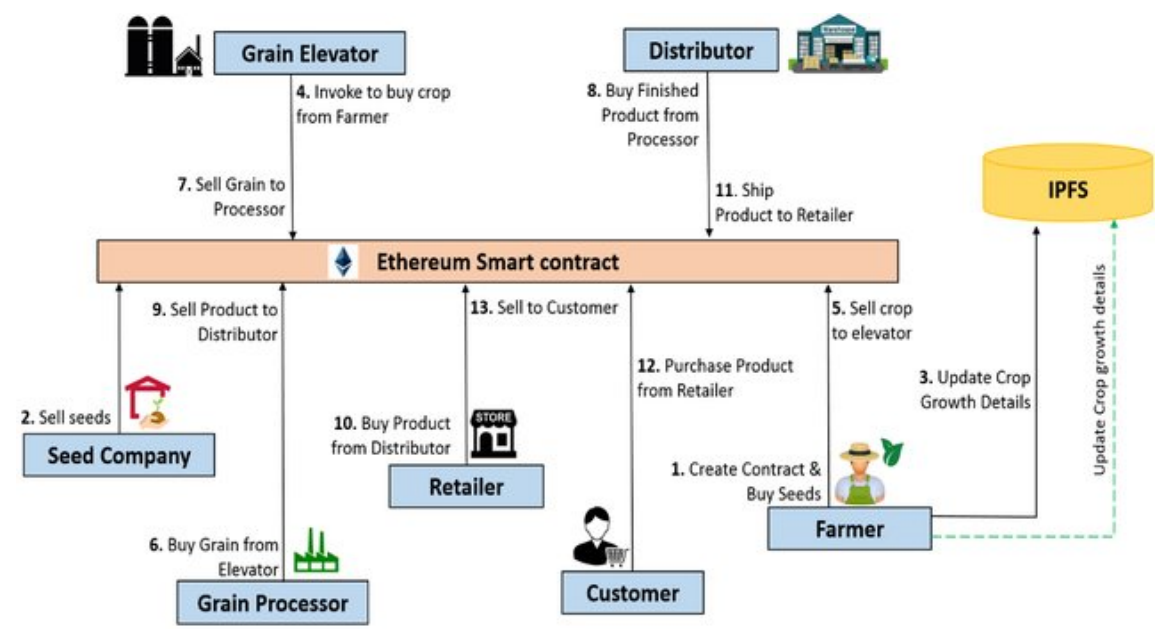

Figure 6: A system overview for automating the Soybean traceability using Ethereum Smart Contracts ${ }^{11}$.

This blockchain framework encompasses seven entities- seed companies, farmers, grain elevators (where grains are monitored for quality), grain processor (converts grain to final product), distributor, retailer and customer. Identifiers such as serialized Global Trade Identification Numbers (GTIN) or equivalents, which include the specific company prefix, are used to identify soybean seeds sold by seed companies. In the agricultural product supply chain, standard identifiers facilitate digital connectivity and tracking capabilities of products and transactions. Farmers buy seeds from seed companies and plant them. The farmer records the details of the crop growth in the decentralized file system, IPFS, at regular intervals. Smart contracts store the IPFS hash of the crop growth images and the time-stamped crop growth images ${ }^{11}$ ). Apart from ensuring supply chain transparency, smart contracts can be deployed to ensure that food items meet certain environmental or social criteria (such as criteria related to sustainability) ${ }^{45}$.

However, smart contracts are by no means a silver bullet. Smart contract failures have already occurred. These contracts have been further classified as prodigal, suicide, and greedy. Prodigal contracts are those that have fallen into the hands of hackers, rerouting the Ethers in this instance. This fraud resulted in crypto-currencies reaching a fraudulent address and becoming the property of the fraudster who was placed between the contracting party and the crypto-intended currency's recipient. Suicide contracts are those that are terminated when the attacker activates an exit requirement. It is possible that an exit clause has been implemented incorrectly, as has already occurred, and the resulting consequences are swift. Under the guise of a legal act, the incorrect party ends up with all the encrypted funds associated with the smart contract. Additionally, it should be noted that insufficient protection of the information contained in one of these contracts results in funds being transferred to unauthorised locations. Greedy contracts may be the result of poor practice or miswriting, but the fact remains that the contracting party will lose legitimacy in order to receive its encrypted currency. It becomes uncontrollable and terminates the contract. This is an illustration of economic loss as a result of a vulnerability failure ${ }^{46}$ and could easily undermine agricultural sustainability blockchain applications.

\section{Potential Role of Geospatial Data}

The data requirements for establishing agricultural commodity provenance, tracking growing and processing conditions along with ensuring food safety standards are being met needs are fulfilled using technological solutions including the Internet-of-Things (IoT), RFID technology and geospatial products among others.

\subsection{Internet of Things (IoT)}

A physical object containing programmable sensors and related software that connects and exchanges data with other devices and systems over the Internet or other communication networks is called the Internet 
of Things (IoT). A smartwatch is an example of the Internet of Things in action. There is a wide range of agricultural applications for IoT technology, especially in terms of monitoring growing conditions for precision agriculture. The IoT devices are linked and communicate with each other via a wireless sensor network. Every device is connected to the internet without human intervention and can transmit data at all times. IoT can be used in conjunction with sensor-based devices to support precision agriculture via surveillance-centric agricultural monitoring systems, smart irrigation-based systems and smart greenhouses among others. Although blockchain technology is not required for IoT devices to operate, its use can provide a design basis for IoT transactions and can assist in building trust, reducing costs, and accelerating transactions ${ }^{23}$.

IoT-based agriculture systems offer the potential of collecting fine-scale information about growing conditions and pest management. IoT can thus support smart agriculture ${ }^{47}$.

An IoT powered agricultural blockchain has been envisaged by Chun-Ting et al. ${ }^{48}$ :

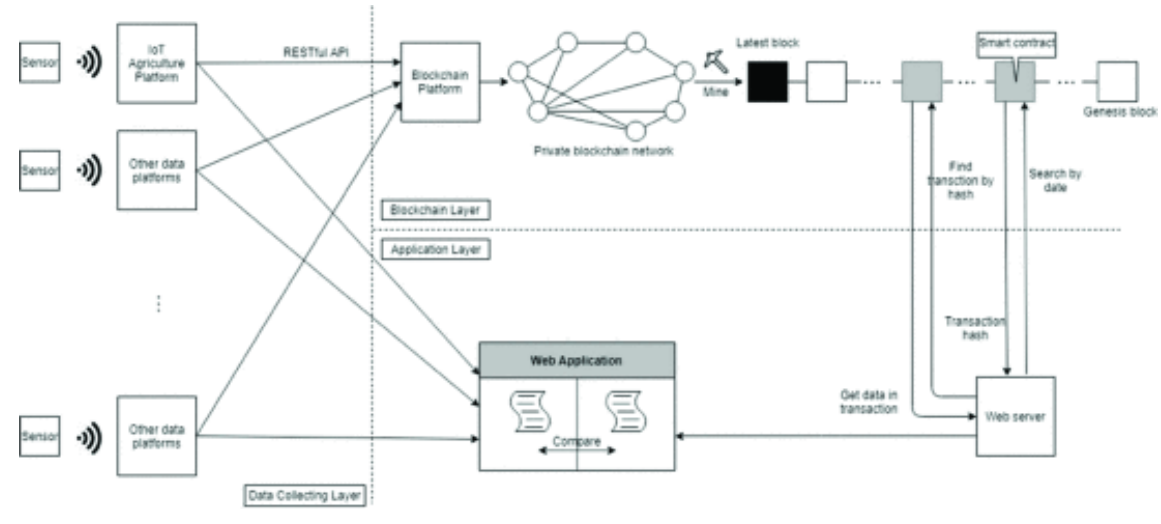

Figure 7: IoT-Powered Agriculture Blockchain System Architecture ${ }^{48}$

Farming is the first link in the agri-food traceability process. IoT smart devices can collect and transmit the traceability data needed in the business process. The traceability information available can store a blockchain-based traceability system. The traceability information may include farming background environment (e.g. soil, water, temperature and humidity quality), farming staff, date, time, origin and application of drug variety, irrigation, fertilizing and pesticides ${ }^{49}$. Startups such as FILAMENT have used blockchain technology to broadcast information obtained from IoTs such as weather data, SMA alerts, machinery protocol and GPS positioning on the farm to support precision agriculture and improve transparency. Aside from agriculture, IoT integrated with blockchain frameworks can also support sustainable aquaculture practices by monitoring rearing conditions (temperature sensors, water level sensors, oxygen sensors, and $\mathrm{pH}$ sensors) for monitoring any environmental changes and actuators (water pump, pond heater, fish feeder, and lighting LED) for regulating the corresponding environment. Sensors and actuators in one fish tank transmit information to the others, forming a complete fish farming environment. Data collected and analyzed by the IoT sensors can then be fed into the blockchain system. Users can have different permissions based on the type of data they wish to access. Additionally, the policy contract differentiates between access control for network administrative changes (network access control) and access control for resources within a business network (business access control) ${ }^{50}$.

\subsection{Incorporating Geospatial Information}

While IoT devices do not need geospatial information to function, the inclusion of geospatial information can both help establish agricultural commodity origins and learn more about cultivation site conditions. How geospatial data could be incorporated within IoT-blockchain applications has been illustrated by Miloudi et al. $(2020)^{51}$ 


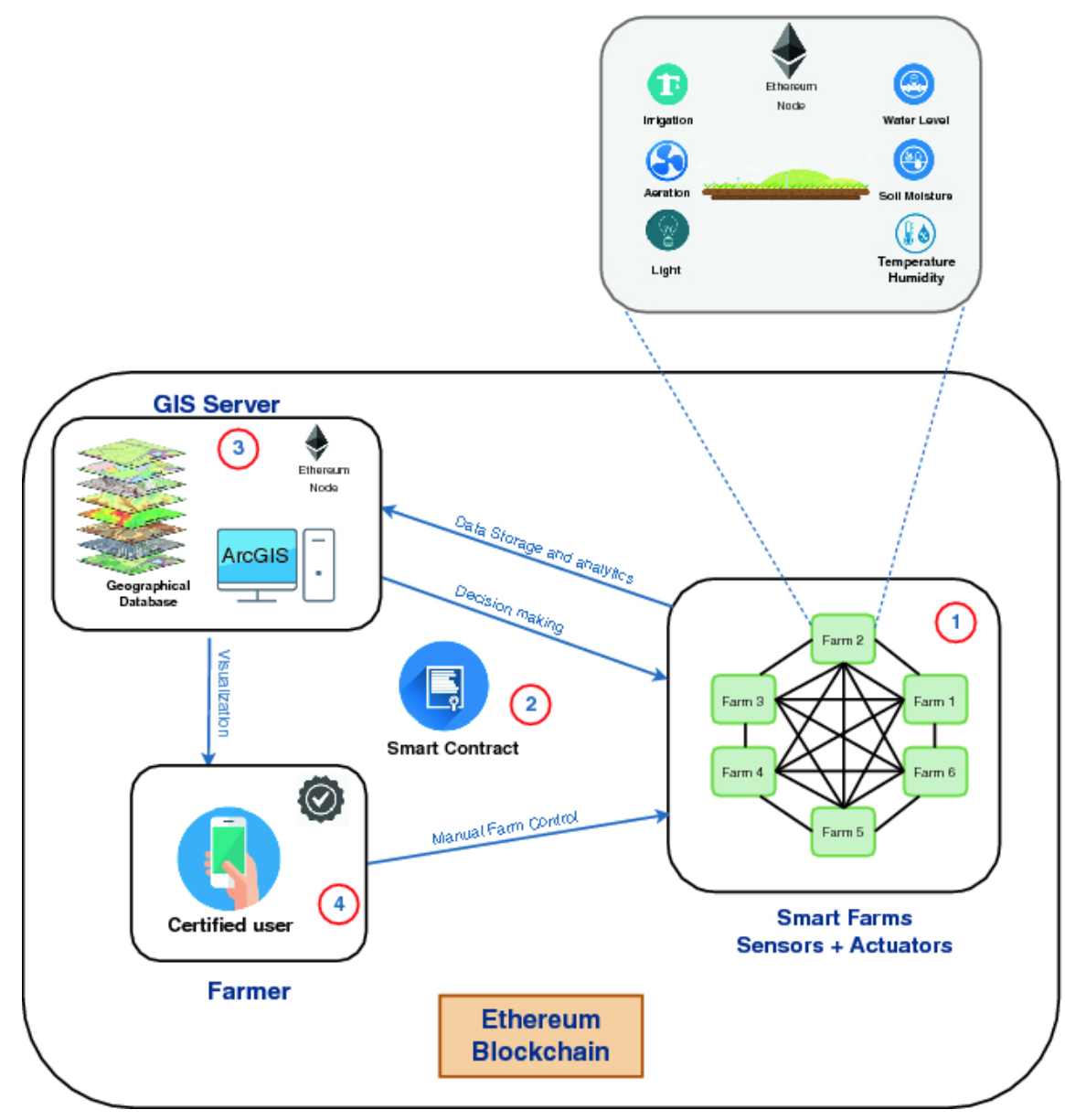

Figure 8: Incorporating Geospatial Information For Smart Farms ${ }^{51}$

Incorporating geospatial data, especially from earth observation (EO) data can identify not only the origins of cash crops such as oil palm but also identify their spread to identify the impact on deforestation. A schema for doing so is shown in figure 9 .

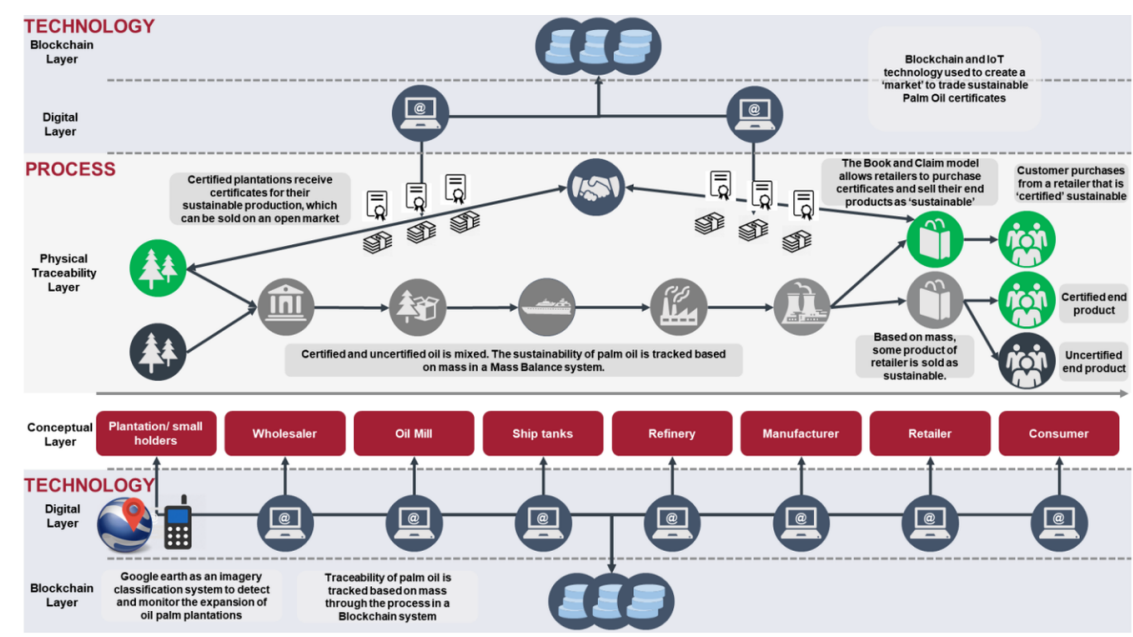


Figure 9: The Conceptual Model Of Incorporating Geospatial Data For Oil Palm Sustainability Modelling Via Blockchains ${ }^{52}$

In spite of the pivotal role EO data plays in identifying the environmental impacts of agriculture, there is virtually no research looking into incorporating publicly available Eo data such as those obtained from Landsat within blockchain frameworks. Hence at this point, it is difficult to say which blockchain frameworks are best suited for developing geospatial blockchains for consistently establishing crop origins and their impacts.

Blockchain technology can enable businesses to comply with legislation and consumer demands, which will create a positive social and environmental impact ${ }^{50}$ and even transform food systems ${ }^{53}$. However for blockchain technologies to be functional, global development and agreement on suitable data standards and governance are needed. Unless we have standard transparency norms for agribusinesses, we can have a situation in which they provide only limited information and even obscure data on commodity sourcing and yet claim to be sustainable or obtain third-party certification ${ }^{53}$.

\section{Conclusions}

Blockchain technology truly allows a pathway to improve sustainability and transparency throughout the agricultural supply chain from farm to fork. For agricultural transparency and supply chain sustainability, permissioned blockchain frameworks such as Hyperledger and permissionless blockchain frameworks such as Ethereum both have their strengths and weaknesses. While IoT data can support establishing provenance and ensuring benchmark growing conditions for meeting sustainability and organic standards, the use of EO data for minimizing deforestation has still not been widely adopted. While blockchain technology has been adopted for a variety of agricultural sustainability applications, but the lack of global data standards can hinder the widespread adoption of blockchain technology.

Acknowledgements : I am grateful to Dr Vallipuram Muthukkumarasamy of Griffith University (Australia) for his guidance.

Bibliography

1. Winkler K, Fuchs R, Rounsevell M, Herold M. Global land use changes are four times greater than previously estimated. Nat Commun. 2021;12(1):2501. doi:10.1038/s41467-021-22702-2

2. Pendrill F, Persson M, Godar J, Kastner T. Deforestation displaced: trade in forest-risk commodities and the prospects for a global forest transition. Environmental Research Letters. Published online March 6, 2019. doi:10.1088/1748-9326/ab0d41

3. Kopittke PM, Menzies NW, Wang P, McKenna BA, Lombi E. Soil and the intensification of agriculture for global food security. Environ Int. 2019;132:105078. doi:10.1016/j.envint.2019.105078

4. Zabel F, Delzeit R, Schneider JM, Seppelt R, Mauser W, Václavík T. Global impacts of future cropland expansion and intensification on agricultural markets and biodiversity. Nat Commun. 2019;10(1):2844. doi:10.1038/s41467-019-10775-z

5. Zhao Z-H, Hui C, He D-H, Li B-L. Effects of agricultural intensification on ability of natural enemies to control aphids. Sci Rep. 2015;5:8024. doi:10.1038/srep08024

6. Richter $\mathrm{CH}$, Custer B, Steele JA, Wilcox BA, Xu J. Intensified food production and correlated risks to human health in the Greater Mekong Subregion: a systematic review. Environ Health. 2015;14:43. doi:10.1186/s12940-015-0033-8

7. zu Ermgassen EKHJ, Ayre B, Godar J, et al. Using supply chain data to monitor zero deforestation commitments: an assessment of progress in the Brazilian soy sector. Environmental Research Letters. 2020;15(3):035003. doi:10.1088/1748-9326/ab6497 
8. Lambin EF, Gibbs HK, Heilmayr R, et al. The role of supply-chain initiatives in reducing deforestation. Nat Clim Chang. 2018;8(2):109-116. doi:10.1038/s41558-017-0061-1

9. Mammadova A, Masiero M, Pettenella D. Embedded deforestation: the case study of the brazilian-italian bovine leather trade. Forests. 2020;11(4):472. doi:10.3390/f11040472

10. Demestichas K, Peppes N, Alexakis T, Adamopoulou E. Blockchain in agriculture traceability systems: A review. Appl Sci. 2020;10(12):4113. doi:10.3390/app10124113

11. Salah K, Nizamuddin N, Jayaraman R, Omar M. Blockchain-Based Soybean Traceability in Agricultural Supply Chain. IEEE Access. 2019;7:73295-73305. doi:10.1109/ACCESS.2019.2918000

12. Yadav VS, Singh AR, Raut RD, Cheikhrouhou N. Blockchain drivers to achieve sustainable food security in the Indian context. Ann Oper Res. Published online November 11, 2021. doi:10.1007/s10479-021-04308-5

13. How the JBS blockchain platform will tackle deforestation in Brazil. Accessed November 14, 2021. https://www.thegrocer.co.uk/the-grocer-vision/how-the-jbs-blockchain-platform-will-tackledeforestation-in-brazil/657838.article

14. Prashar D, Jha N, Jha S, Lee Y, Joshi GP. Blockchain-Based Traceability and Visibility for Agricultural Products: A Decentralized Way of Ensuring Food Safety in India. Sustainability. 2020;12(8):3497. doi:10.3390/su12083497

15. Aronzon S. Blockchain and geographical indications: A natural fit? SSRN Journal. Published online 2019. doi:10.2139/ssrn.3627352

16. Martos V, Ahmad A, Cartujo P, Ordoñez J. Ensuring Agricultural Sustainability through Remote Sensing in the Era of Agriculture 5.0. Appl Sci. 2021;11(13):5911. doi:10.3390/app11135911

17. Kamilaris A, Fonts A, Prenafeta-Boldú FX. The rise of blockchain technology in agriculture and food supply chains. Trends Food Sci Technol. 2019;91:640-652. doi:10.1016/j.tifs.2019.07.034

18. Galvez JF, Mejuto JC, Simal-Gandara J. Future challenges on the use of blockchain for food traceability analysis. TrAC Trends in Analytical Chemistry. 2018;107:222-232. doi:10.1016/j.trac.2018.08.011

19. Xu J, Guo S, Xie D, Yan Y. Blockchain: A new safeguard for agri-foods.Artificial Intelligence in Agriculture. 2020;4:153-161. doi:10.1016/j.aiia.2020.08.002

20. Tsolakis N, Niedenzu D, Simonetto M, Dora M, Kumar M. Supply network design to address United Nations Sustainable Development Goals: A case study of blockchain implementation in Thai fish industry. J Bus Res. 2021;131:495-519. doi:10.1016/j.jbusres.2020.08.003

21. Chan KY, Abdullah J, Shahid A. A Framework for Traceable and Transparent Supply Chain Management for Agri-food Sector in Malaysia using Blockchain Technology. ijacsa. 2019;10(11). doi:10.14569/IJACSA.2019.0101120

22. M S H, R S, M R. Block chain based agricultural supply chain-A review. Global Transitions Proceedings. 2021;2(2):220-226. doi:10.1016/j.gltp.2021.08.041

23. Torky M, Hassanein AE. Integrating blockchain and the internet of things in precision agriculture: Analysis, opportunities, and challenges.Computers and Electronics in Agriculture. Published online September 2020:105476. doi:10.1016/j.compag.2020.105476

24. Ronaghi MH. A blockchain maturity model in agricultural supply chain.Information Processing in Agriculture. 2021;8(3):398-408. doi:10.1016/j.inpa.2020.10.004

25. Shoker A. Blockchain technology as a means of sustainable development. One Earth. 2021;4(6):795-800. doi:10.1016/j.oneear.2021.05.014 
26. Kshetri N. Blockchain and sustainable supply chain management in developing countries. Int $J$ Inf Manage. 2021;60:102376. doi:10.1016/j.ijinfomgt.2021.102376

27. Bringing traceability and accountability to the supply chain through the power of Hyperledger Sawtooth's distributed ledger technology. Accessed November 22, 2021. https://sawtooth.hyperledger.org/examples/seafood.html

28. Xiong H, Dalhaus T, Wang P, Huang J. Blockchain technology for agriculture: applications and rationale. Front Blockchain. 2020;3. doi:10.3389/fbloc.2020.00007

29. Wang L, Xu L, Zheng Z, et al. Smart Contract-Based Agricultural Food Supply Chain Traceability. IEEE Access. 2021;9:9296-9307. doi:10.1109/ACCESS.2021.3050112

30. Collart AJ, Canales E. How might broad adoption of blockchain-based traceability impact theU.S. fresh produce supply chain? Applied Economic Perspectives and Policy. Published online January 14, 2021. doi:10.1002/aepp.13134

31. UCC COFFEE LAUNCHES UK'S FIRST FARMER CONNECT BLOCKCHAIN PARTNERSHIP. Accessed November 17, 2021. https://www.ucc-coffee.co.uk/ucc-coffee-launches-uks-first-farmer-connectblockchain-partnership/

32. Kamath R. Food Traceability on Blockchain: Walmart's Pork and Mango Pilots with IBM.The JBBA. 2018;1(1):1-12. doi:10.31585/jbba-1-1-(10)2018

33. Jaiyen J, Pongnumkul S, Chaovalit P. A Proof-of-Concept of Farmer-to-Consumer Food Traceability on Blockchain for Local Communities. In: 2020 International Conference on Computer Science and Its Application in Agriculture (ICOSICA). IEEE; 2020:1-5. doi:10.1109/ICOSICA49951.2020.9243172

34. Marchese A, Tomarchio O. An Agri-Food Supply Chain Traceability Management System based on Hyperledger Fabric Blockchain. In: Proceedings of the 23rd International Conference on Enterprise Information Systems. SCITEPRESS - Science and Technology Publications; 2021:648-658. doi: $10.5220 / 0010447606480658$

35. Hao Z, Mao D, Zhang B, Zuo M, Zhao Z. A novel visual analysis method of food safety risk traceability based on blockchain. Int J Environ Res Public Health. 2020;17(7). doi:10.3390/ijerph17072300

36. Chen C-L, Shang X, Tsaur W-J, et al. An Anti-Counterfeit and Traceable Management System for Brand Clothing with Hyperledger Fabric Framework.Symmetry. 2021;13(11):2048. doi:10.3390/sym13112048

37. Miatton F, Amado L. Fairness, Transparency and Traceability in the Coffee Value Chain through Blockchain Innovation. In: 2020 International Conference on Technology and Entrepreneurship - Virtual (ICTE-V). IEEE; 2020:1-6. doi:10.1109/ICTE-V50708.2020.9113785

38. Zhang L, Zeng W, Jin Z, Su Y, Chen H. A research on traceability technology of agricultural products supply chain based on blockchain and IPFS.Security Comm Networks. 2021;2021:1-12. doi:10.1155/2021/3298514

39. Pranto TH, Noman AA, Mahmud A, Haque AB. Blockchain and smart contract for IoT enabled smart agriculture. PeerJ Comput Sci. 2021;7:e407. doi:10.7717/peerj-cs.407

40. Thakur V, Doja MN, Dwivedi YK, Ahmad T, Khadanga G. Land records on Blockchain for implementation of Land Titling in India. Int J Inf Manage. 2020;52:101940. doi:10.1016/j.ijinfomgt.2019.04.013

41. Grecuccio J, Giusto E, Fiori F, Rebaudengo M. Combining Blockchain and IoT: Food-Chain Traceability and Beyond. Energies. 2020;13(15):3820. doi:10.3390/en13153820

42. Jha N, Prashar D, Khalaf OI, Alotaibi Y, Alsufyani A, Alghamdi S. Blockchain based crop insurance: A decentralized insurance system for modernization of indian farmers. Sustainability. 2021;13(16):8921. doi: $10.3390 /$ su13168921 
43. Iyer V, Shah K, Rane S, Shankarmani R. Decentralised Peer-to-Peer Crop Insurance. In:Proceedings of the 3rd ACM International Symposium on Blockchain and Secure Critical Infrastructure. ACM; 2021:3-12. doi:10.1145/3457337.3457837

44. Shih D-H, Lu K-C, Shih Y-T, Shih P-Y. A simulated organic vegetable production and marketing environment by using ethereum. Electronics. 2019;8(11):1341. doi:10.3390/electronics8111341

45. dos Santos R, Torrisi N, Yamada E, Pantoni R. IGR Token-Raw Material and Ingredient Certification of Recipe Based Foods Using Smart Contracts.Informatics. 2019;6(1):11. doi:10.3390/informatics6010011

46. Salmerón-Manzano E, Manzano-Agugliaro F. The role of smart contracts in sustainability: worldwide research trends. Sustainability. 2019;11(11):3049. doi:10.3390/su11113049

47. Awan SH, Ahmad S, Khan Y, Safwan N, Qurashi SS, Hashim MZ. A Combo Smart Model of Blockchain with the Internet of Things (IoT) for the Transformation of Agriculture Sector. Wireless Pers Commun. 2021;121(3):2233-2249. doi:10.1007/s11277-021-08820-6

48. Chun-Ting P, Meng-Ju L, Nen-Fu H, Jhong-Ting L, Jia-Jung S. Agriculture Blockchain Service Platform for Farm-to-Fork Traceability with IoT Sensors. In:2020 International Conference on Information Networking (ICOIN). IEEE; 2020:158-163. doi:10.1109/ICOIN48656.2020.9016535

49. Feng H, Wang X, Duan Y, Zhang J, Zhang X. Applying blockchain technology to improve agri-food traceability: A review of development methods, benefits and challenges. J Clean Prod. 2020;260:121031. doi:10.1016/j.jclepro.2020.121031

50. Hang L, Ullah I, Kim D-H. A secure fish farm platform based on blockchain for agriculture data integrity. Computers and Electronics in Agriculture. 2020;170:105251. doi:10.1016/j.compag.2020.105251

51. Miloudi L, Rezeg K, Kazar O, Miloudi MK. Smart sustainable farming management using integrated approach of iot, blockchain \& geospatial technologies. In: Ezziyyani M, ed. Advanced Intelligent Systems for Sustainable Development (AI2SD'2019) Volume 2 - Advanced Intelligent Systems for Sustainable Development Applied to Agriculture and Health. Vol 1103. Advances in intelligent systems and computing. Springer International Publishing; 2020:340-347. doi:10.1007/978-3-030-36664-3_38

52. Hirbli T.Palm Oil Traceability: Blockchain Meets Supply Chain. Published online June 1, 2018.

53. Yang L, Zhang J, Shi X. Can blockchain help food supply chains with platform operations during the COVID-19 outbreak? Electron Commer Res Appl. 2021;49:101093. doi:10.1016/j.elerap.2021.101093 